\title{
PENERAPAN MOTION GRAPHIC FLAT DESAIN PADA COMPANY PROFILE SMP MUHAMMADIYAH 1 MARGA TIGA
}

\author{
${ }^{1}$ Nur Oktavia, ${ }^{2}$ Untoro Apsiswanto, ${ }^{3}$ Usep Saprudin \\ ${ }^{1}$ Nur Oktavia, STMIK Dharma Wacana,oktavianur71@gmail.com \\ ${ }^{2}$ Untoro Apsiswanto, STMIK Dharma Wacana, untorolampung@gmail.com \\ ${ }^{3}$ Usep Saprudin, STMIK Dharma Wacana, usepkreatif@gmail.com
}

\begin{abstract}
ABSTRAK
SMP Muhammadiyah 1 Marga Tiga merupakan sekolah swasta di Marga Tiga yang belum mempunyai media informasi untuk menyampaikan informasi yang relevan. Sehingga di butuhkan company profile untuk memberikan infomasi agar lebih dikenal. Motion graphic adalah salah satu cabang ilmu desain grafi bagian desain berbentuk seperti, raut, ukuran, arah, tekstur yang terdapat di dalamnya, diberi pergerakan agar tampak hidup. company profile digunakan untuk memberikan infomasi agar lebih dikenal terutama dalam membuat Motion Graphic Flat Desain Pada Company profile SMP Muhammadiyah 1 Marga Tiga.
\end{abstract}

Kata Kunci : Motion Graphic Flat Desain, Company profile, Video.

\section{PENDAHULUAN}

Motion Graphic adalah jenis video yang populer digunakan dalam mempresentasikan data. Menurut Umam (2016: 8) "motion graphic merupakan salah satu cabang ilmu desain grafis, dimana dalam motion, elemen elemen desain seperti bentuk, raut, ukuran, arah, tekstur yang terdapat di dalamnya, dengan secara sengaja digerakkan atau diberi pergerakan agar tampak hidup". Motion graphic, elemen dari desain yang diberi gerakan sehingga terlihat dinamis dan ditampilkan melalui media audio visual. SMP Muhammadiyah 1 Marga Tiga adalah salah satu sekolah swasta di MargaTiga yang belum mempunyai media informasi untuk menyampaikan informasi yang relevan. Maka dari itu, company profile dibutuhkan untuk memberikan infomasi agar lebih dikenal. Dalam Penyampaian Informasi di SMP Muhammadiyah 1 Marga Tiga masih menggunakan media sosial dan banner.

\section{LITERATUR REVIEW}

Menurut Jubilee Enterprise (2015) "Company Profile adalah gambaran khusus tentang sebuah perusahaan yang berkerja secara teratur dengan tujuan untuk mencari keuntungan". Sedangkan Menurut Michael Sega Gumelar (2016)" Motion graphic berasal dari kata motion picture yang artinya motion adalah bergerak dan pictures adalah gambar". Bila diterjemahkan memang sama, tetapi memiliki arti (semantic) yang berbeda, karena simbol (semiontics) kata yang mewakilinya berbeda.
Wardhani (2014:3) dalam jurnalnya menjelaskan: "Motion graphics adalah grafis yang menggunakan video dan atau animasi untuk menciptakan ilusi dari gerak ataupun transformasi. Adapula pengertian lain dikemukakan menurut Achmad Mujahid Syayaf (2018) "Flat design adalah Implementasi gaya minimalis dalam dunia desain grafis".

\section{METODOLOGI}

\subsection{Tahapan Penelitian}

Pada tahap penelitian ini menggunakan metode pengembangan MDLC (Media Development Life Cycle) yaitu :

1. Tahap concept (pengonsepan)

2. Tahap pembuatan Design (perancangan).

3. Tahap pengumpulan bahan Material collection

4. Tahap penyatuan Assembly

5. Tahap pengujian Testing

\subsection{Data}

Karakter :

a) Anansya adalah seorang siswa yang diperankan oleh siswa SMP.

b) Kepala Sekolah Adalah Seseorang yang diperankan oleh Bapak Sutoto, S.Pd.M.M.Pd.

c) Wakasis adalah Wakil Kepala sekolah yang diperankan oleh Bapak Mukayan, S.Pd

\section{HASIL DAN PEMBAHASAN}

a) Concept merupakan tahap awal dari pengembangan animasi motion graphic ini:

\begin{tabular}{|l|l|l|l|}
\hline Karakter & Narasi & Adegan & $\begin{array}{l}\text { Durasi } \\
(60\end{array}$ \\
\hline
\end{tabular}




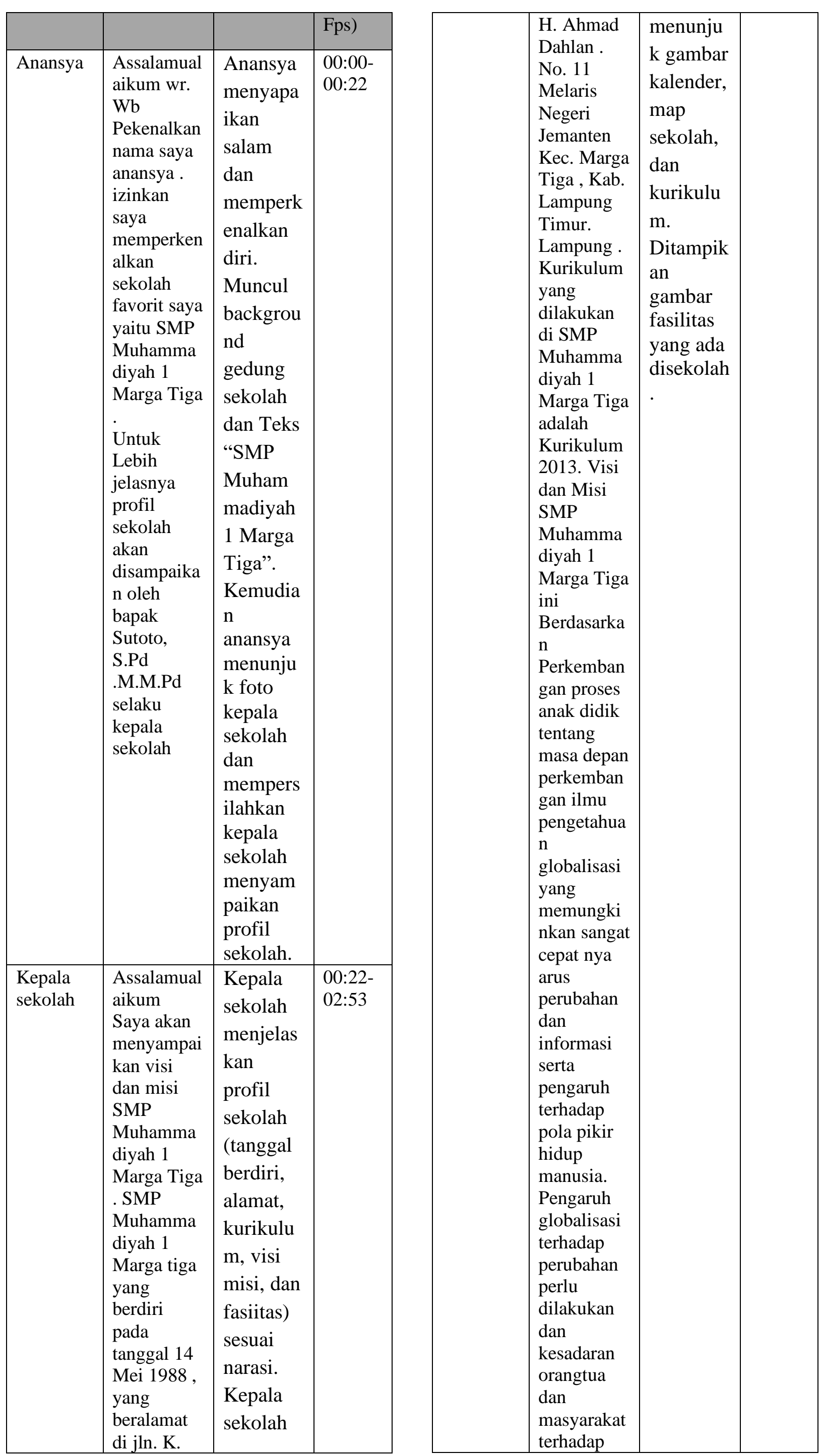




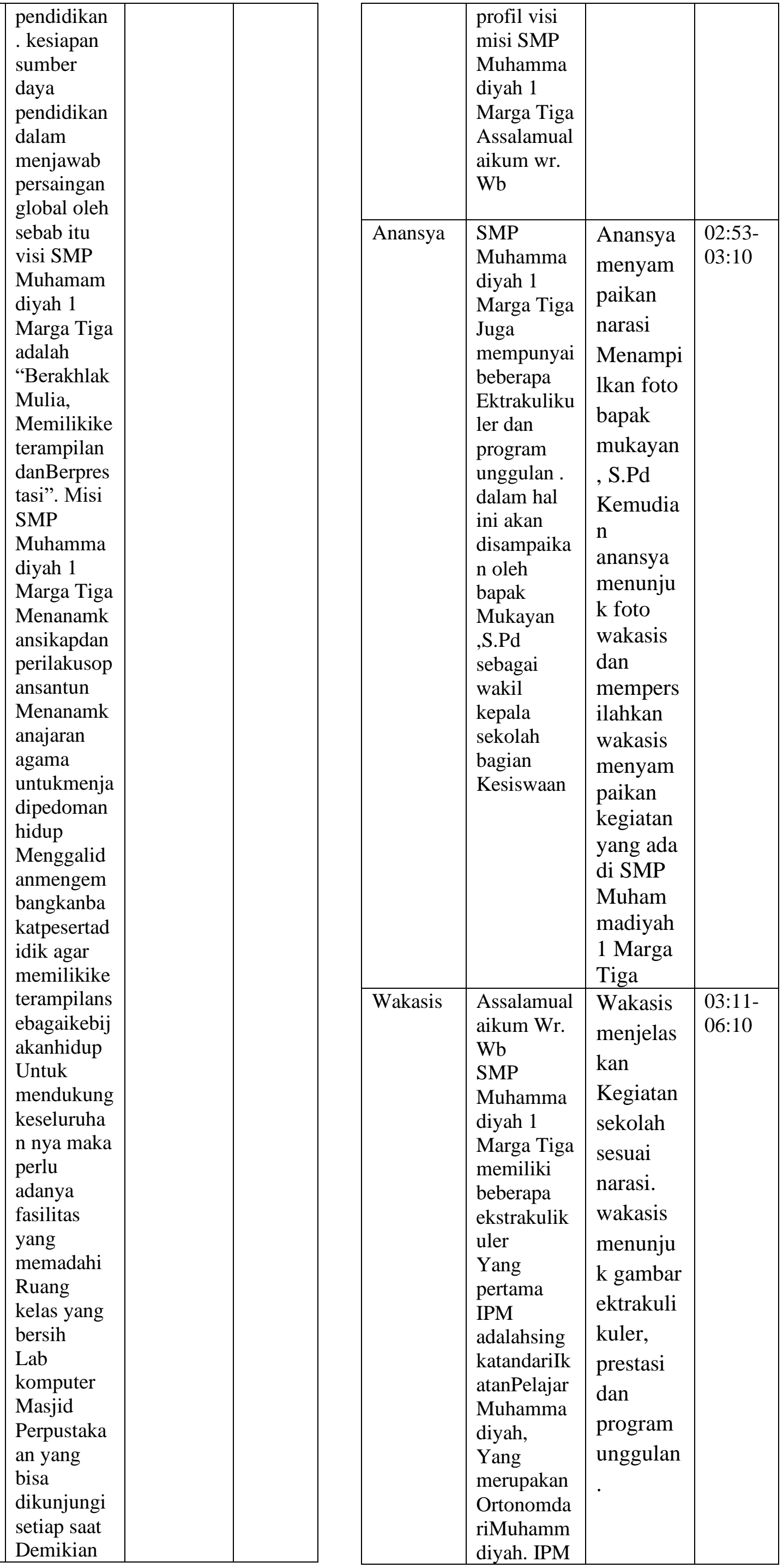




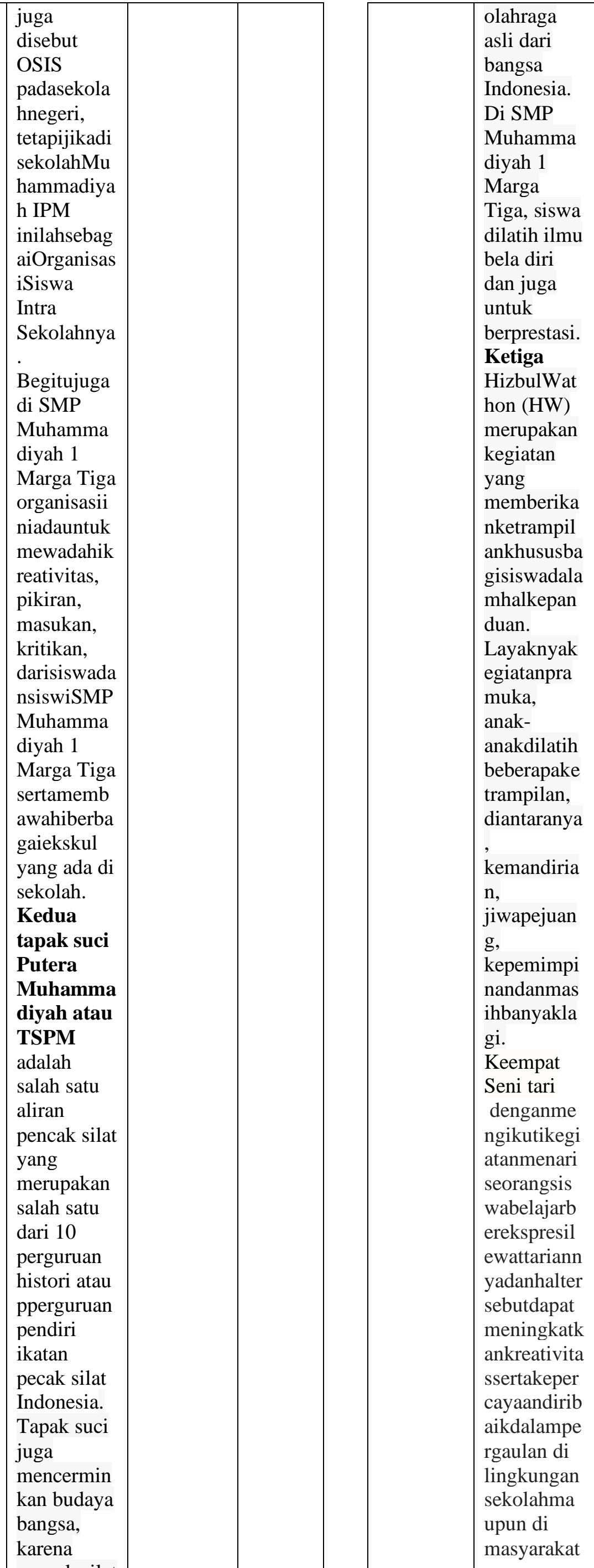




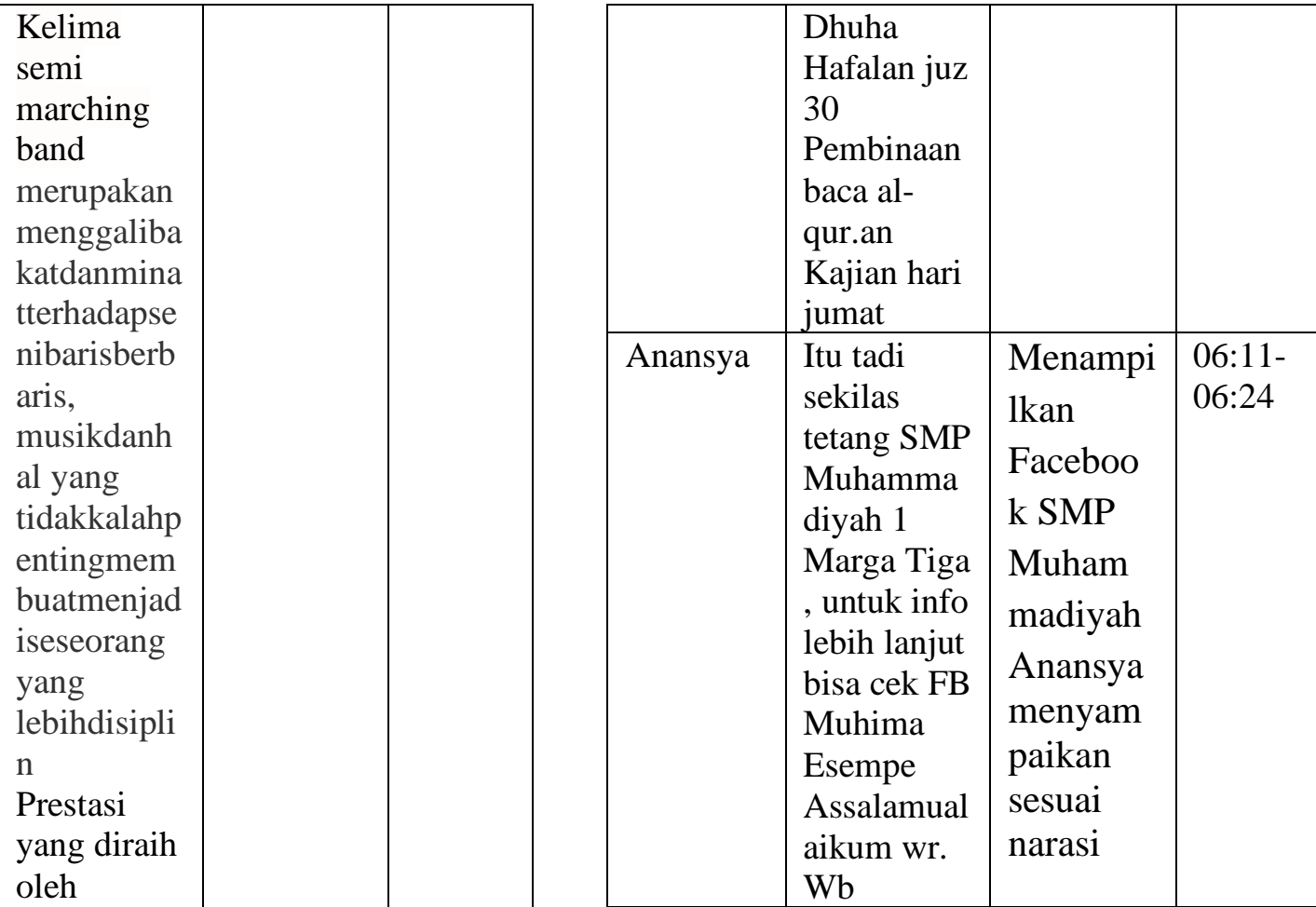

oleh

siswa/siswi

SMP

Muhamma

diyah 1

Marga Tiga

diantaranya

Juara 1

O2SN

pecak silat

tunggal

putra

tingkat

SMP kab.

lampung

Timur,

Tahun

2019

Juara 2

Tari kreasi

Festival

Waykamba

s ,2019

Juara 3

Da'i,

Gembyar

Ekstrakulik

uler SMAN

1

Sekampung

, 2019

Bukan

Hanya itu

SMP

Muhamma

diyah 1

Marga Tiga

juga

mempunyai

program

Unggulan

yaitu

Sholat

b) Pada tahap ini pembuatannya menggunakan storyboard. Storyboard ini harus sesuai dengan concept. Storyboard diperlukan karena digunakan sebagai acuan untuk proses produksi. Adapun tahapanya yaitu:

\begin{tabular}{|c|c|c|}
\hline StoryBoard & Durasi & Audio \\
\hline Assala MUAA Aitam Wr.wB & $\begin{array}{l}\text { 00:00- } \\
00: 04\end{array}$ & $\begin{array}{l}\text { Assalamual } \\
\text { aikum wr. } \\
\mathrm{Wb}\end{array}$ \\
\hline (8) ANASYA & $\begin{array}{l}00: 05- \\
00: 10\end{array}$ & $\begin{array}{l}\text { Pekenalkan } \\
\text { nama saya } \\
\text { annasya . }\end{array}$ \\
\hline$\sqrt{1 i}$ & $\begin{array}{l}00: 11- \\
00: 17\end{array}$ & $\begin{array}{l}\text { izinkan } \\
\text { saya } \\
\text { memperken } \\
\text { alkan } \\
\text { sekolah } \\
\text { favorit saya } \\
\text { yaitu SMP } \\
\text { Muhamma } \\
\text { diyah 1 } \\
\text { Marga Tiga }\end{array}$ \\
\hline
\end{tabular}

c) Pengumpulan Materi yaitu mengumpulkan file berbentuk teks, gambar, audio maupun file lainnya terkait pembuatan animasi ini :

1. Layers Karakter Anansya

Alis, Body, Lengan atas kanan, Lengan atas kiri, Lengan bawah kanan, Lengan bawah kiri, Sepatu kanan, Sepatu kiri, Jari tangan kanan, 
Jari tangan kiri, Jari tangan kanan 2,Jari tangan kri 2.

2. Layers Karakter kepala sekolah Body, Paha kiri, Paha kanan, Kaki kanan, Kaki kiri, Lengan atas kanan, Lengan atas kiri, Lengan bawah kanan, Lengan bawah kiri, Sepatu kanan, Sepatu kiri, Jari tangan kanan, Jari tangan kiri, Jari tangan kanan 2, Jari tangan kiri 2, Jari tangan kanan 3, Jari tangan kiri 3, Kaos kaki kanan, Kaos kaki kiri.

3. Layers Karakter Waka Kesiswaan Body, Lengan kanan, Lengan kiri, Tangan kanan , Jari tangan kanan , Jari tangan kiri, Paha kaki kanan, Paha kaki kiri, Kaki kiri, Kaki kanan, Sepatu kanan, Sepatu kiri, Kaos kaki kanan ,Kaos kaki kiri.

4. Layers Background gedung sekolah Bendera, Jendela,Tiang, Pintu 2, atap

5. Layers Background ruang kepala sekolah Diagram ,Kursi kayu 1,Kursi kayu 2 Lemari buku Note 1 Note 2 Sertifikat 1 Sertifikat 2 Bingkai dan foto Tempat alat tulis Tumpukan dokumen Meja Pot bunga Kursi Gorden Tembok Lantai.

d) Assembly

Fase produksi (tahap ilustrasi) :

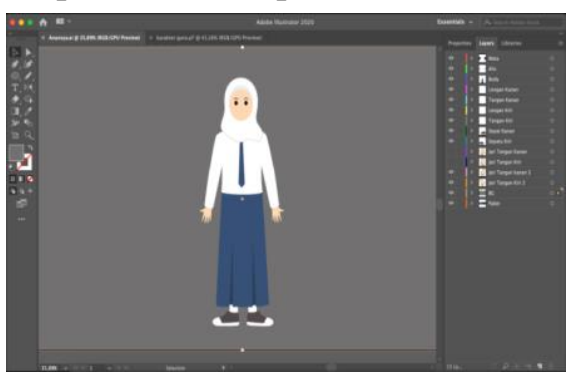

Gambar 1 karakter anasya

Face produksi (tahap animasi) :

\begin{tabular}{|c|c|}
\hline Adegan & Keteragan \\
\hline & $\begin{array}{l}\text { Background : } \\
\text { gradien warna ungu } \\
\text { dan hijau. } \\
\text { Star : Camera shake } \\
\text { Shape : Camera shake } \\
\text { Karakter anansya } \\
\text { Mata kanan : } \\
\text { Keyframe dan looping } \\
\text { Mata kiri : Keyframe } \\
\text { dan looping } \\
\text { Mulut : Keyframe dan } \\
\text { looping } \\
\text { Tangan dan kaki: } \\
\text { Plug-in Duik Bassel } 2 \\
\text { Teks : Bounce }\end{array}$ \\
\hline
\end{tabular}

Gambar 2 produksi scene 14
Face produksi (tahap rendering awal) :

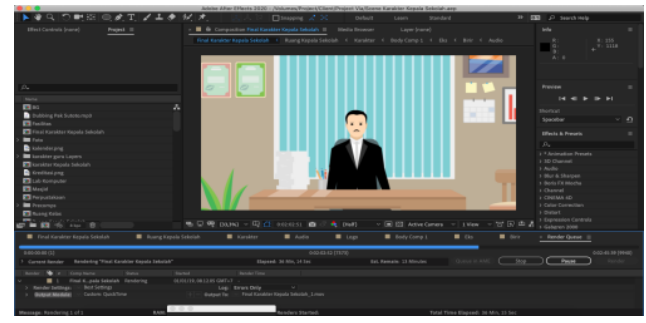

Gambar 3 Rendering Awal

Fase pasca-produksi :

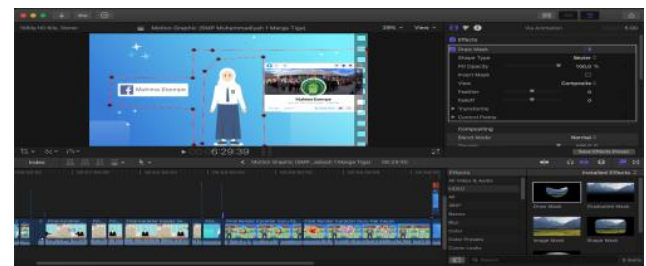

Gambar 4. Editing Video

e) Testing(pengujian)

\begin{tabular}{|l|l|l|}
\hline No. & Nama Software & Keterangan \\
\hline 1 & Film \& TV (PC) & Valid \\
& & \\
\hline 2 & $\begin{array}{l}\text { VLC Media Player } \\
\text { (PC) }\end{array}$ & Valid \\
\hline & & \\
\hline
\end{tabular}

5. CONCLUSION

1) SMP Muhammadiyah 1 Marga Tiga merupakan sekolah di Marga Tiga yang belum mempunyai media informasi untuk menyampaikan informasi yang relevan. Maka dari itu, company profile dibutuhkan untuk memberikan infomasi agar lebih dikenal. Dalam Penyampaian Informasi di SMP Muhammadiyah 1 Marga Tiga masih menggunakan media sosial dan banner.

2) Sistem yang dibuat ini akan membantu pihak sekolah dalam memberikan informasi tentang sekolah kepada masyarakat, dan dengan sistem ini juga dapat membantu pengunjung atau masyarakat untuk mengetahui informasi tanpa mengenal jarak dan waktu.

\section{REFERENCES}

Enterprise, J. (2018). Otodidak Adobe Illustrator. Jakarta.

Fujianto, R. Z., \& Antoni, C. (2020). Produksi

Dan Efektivitas Motion Graphic

Sebagai Media Promosi Zetizen 
Batam Pos. Jurnal Of Digital

Education, Comunication, And Arts.

Gumelar, M. (2016). MOTION GRAPHIC :

Bouncing Ball Non Kartun .

Kausar, A., Sutiawan, Y. F., \& Rosalina, V. (2015). Perancangan Video Company Profile Kota Serang Dengan Teknik Editing Menggunakan Adobe Premier Pro Cs 5. Jurnal Prosisko.

Maryono, Y. (2008). Teknologi Informasi \& Komunikasi.

Mustika. (2018). Rancang Bangun Aplikasi Sumsel Meseum Berbasis Mobile Menggunakan Metode Pengembangan Multimedia Development Life Cycle (MDLC). Jurnal Mikrotik .

Mustika, Adhy Sugara, P. E., \& Pratiwi, M. (2017). Pengembangan Media Pembelajaran Interaktif Dengan Menggunkan Metode Multimedia Develoment Life Cycle. Jurnal Online Informatika.

Purwoko, J. (2016). Implementasi Teknik Motion Graphic Dengan After Effect Pada Sebuah Iklan. Naskah Publikasi.

Rizal, M., Syafar, A., \& Zuhaer, H. (2019). Perancangan Company Profile Berbasis Motion Graphic Sebagai Media Promosi Klinik Hilal Medika Makasar. Seminar Nasional, Sistem Informasi Dan Teknik Informatika .

Supriyadi . (2019). Pemanfaatan Plugin After Effect Untuk Produksi Film

Wardhani, Rahmi Kesuma. 2014. Perancangan Video Dokumenter Autisme. Vol 3(1): 3 